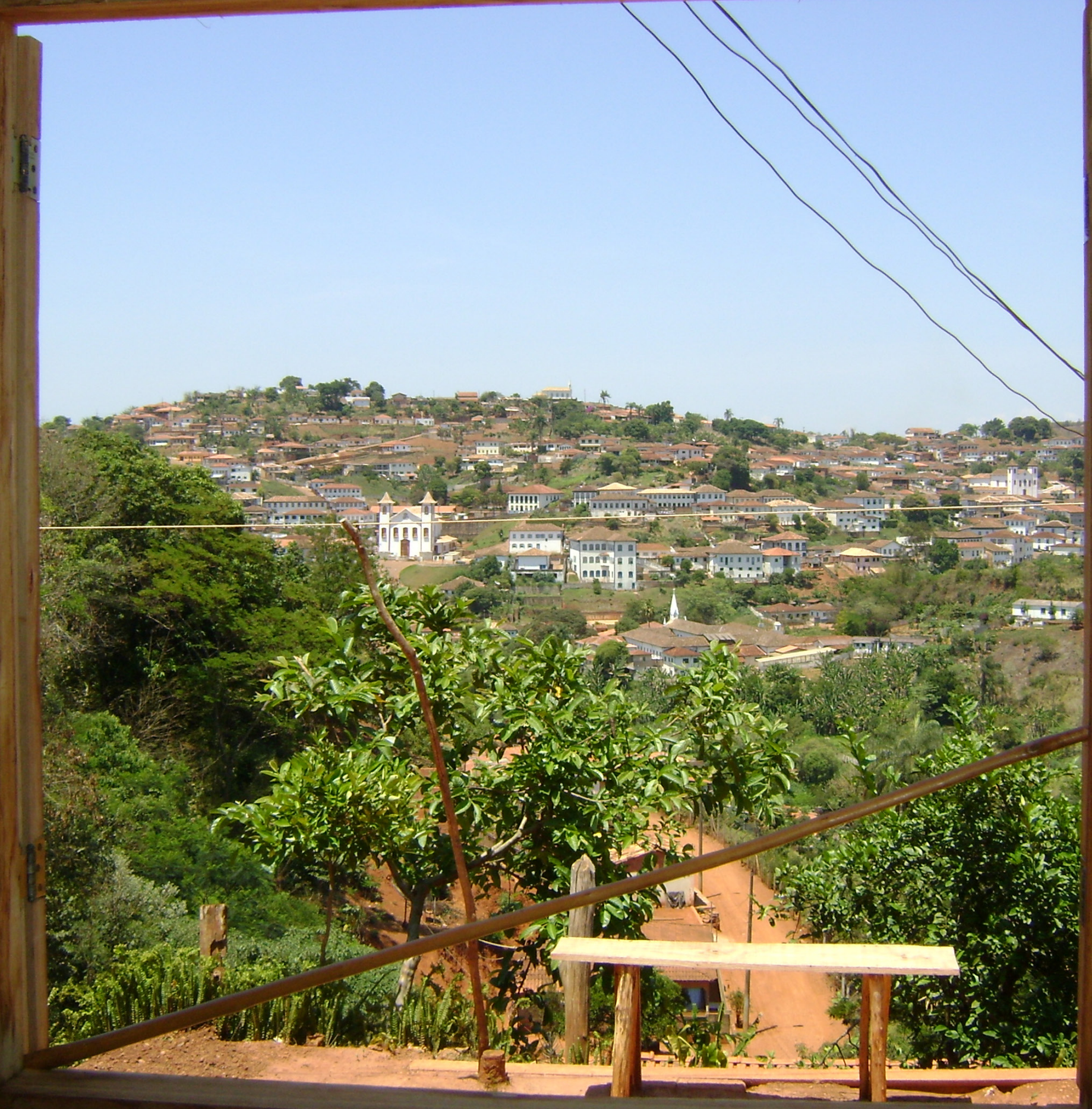




\section{UM PLANO PARA A PAISAGEM CULTURAL DO SERRO, BRASIL: NOVAS POSSIBILIDADES PARA O PATRIMÔNIO}

\section{Leonardo Barci Castriota}

Arquiteto, urbanista e doutor em Filosofia, professor titular da Escola de Arquitectura

\section{RESUMO}

Dentro da perspectiva aberta pela expansão do conceito de patrimônio, algumas novas ideias desempenharam um papel inovador. Uma delas é a "paisagem cultural", combinando aspectos tangíveis e intangíveis do conceito, muitas vezes considerados separadamente, indicando interações significativas entre o homem e o meio ambiente. Este conceito parece oferecer uma perspectiva rica quando se aplica às ideias tradicionais no campo da preservação. A partir deste entendimento ampliado, parece possível propor estratégias integradas de intervenção nos centros históricos, que podem oferecer respostas mais completas ao complexo desafio de preservação urbana. Como estudo de caso, este trabalho apresenta um plano produzido para a cidade de Serro (MG, Brasil), um projeto de recuperação de práticas agrícolas tradicionais que servem como ferramenta para tratar e preservar de maneira sustentável a paisagem cultural de um núcleo urbano protegido. 


\section{RESUMEN}

Dentro de la perspectiva abierta por la expansión del concepto de patrimonio, algunas nuevas ideas han jugado un papel innovador. Una de ellas será el "paisaje cultural" que combina aspectos tangibles e intangibles del concepto, a menudo considerado por separado, indicando las interacciones significativas entre el hombre y el medio ambiente. Este concepto parece ofrecer una perspectiva rica cuando se aplica también a las ideas tradicionales del campo de la conservación. A partir de este entendimiento ampliado, parece posible proponer estrategias integradas de intervención sobre los centros históricos que pueden ser respuestas más completas al complejo reto de la conservación urbana. Como estudio de caso, este artículo presenta un plan producido para la ciudad de Serro (MG, Brasil), un proyecto de rescate de las prácticas agrícolas tradicionales que servirá de insumo para tratar y preservar de manera sostenible el paisaje cultural de un núcleo urbano protegido.

Palabras clave: paisaje cultural, plano, gestión, Brasil

\section{ABSTRACT}

Within the perspective opened by the expansion of the concept of heritage, some new ideas have played an innovative role. One will be the "cultural landscape" that combines inextricably tangible and intangible aspects of the concept, often considered separately, indicating significant interactions between man and the environment. This concept seems to offer a rich perspective when applied to traditional ideas of the field of conservation. From this expanded understanding, it seems possible to propose integrated strategies of intervention in historical centers that can be more comprehensive responses to the complex challenge of urban conservation. As a case study, this paper presents a plan produced for the city of Serro (MG, Brazil) that tries to sustainably preserve the cultural landscape of a protected village in the hinterlands of Brazil, by rescuing its traditional agricultural practices.

Key words: cultural landscape, planning, management, Brazil 
Con la noción de paisaje cultural, el patrimonio alcanzó una escala territorial a la vez que la inclusión de componentes de naturaleza diversa, conjugando lo natural y lo cultural, lo material y lo inmaterial.

CONTI, 2014

\section{INTRODUÇÃO}

Dentro da perspectiva aberta nas últimas décadas pela ampliação do conceito de patrimônio ${ }^{1}$, algumas novas ideias têm desempenhado um papel decisivo e inovador. Uma delas vai ser a de "paisagem cultural" que, desenvolvida pela UNESCO desde o início dos anos 1990, combina de forma inextricável os aspectos materiais e imateriais do conceito, muitas vezes pensados separadamente, indicando as interações significativas entre o homem e o meio ambiente natural. Com isso, esse conceito parece oferecer uma rica perspectiva quando aplicada também às ideias tradicionais do campo da preservação, podendo servir para ampliar a perspectiva de visada sobre os próprios centros históricos, permitindo leituras que compreendem justamente as interações entre os aspectos natural e cultural, material e imaterial desses conjuntos, muitas vezes ignoradas (FOWLER, 2003). A partir desta compreensão ampliada, parece-nos possível também se propor estratégias integradas de intervenção que, ao combinar esses diversos aspectos, terminam por constituir respostas completas ao complexo desafio da conservação urbana.

Para ilustrar essas possibilidades, vamos tomar o caso da cidade do Serro, localizada no "Distrito do Diamante", em Minas Gerais, a 255 quilômetros ao Norte de Belo Horizonte, e uma das poucas cidades da região da mineração a ter sua economia marcada também pela agricultura, desde o início da ocupação. Um dos primeiros conjuntos urbanos a ser tombado nacionalmente pelo IPHAN, ainda em 1938, o Serro apresenta um excepcional conjunto arquitetônico, ao lado de fortes elementos naturais - a Serra do Espinhaço, matas e sítios arqueológicos, e bens culturais imateriais de grande importância, ligados tanto à religiosidade, quanto à sua longa tradição rural, tais como o conhecido "Queijo do Serro", registrado como patrimônio nacional em 2008. Esses elementos vão se combinar numa

1 A esse respeito, confira $\mathrm{CHOAY}, 2000$ 
rica paisagem cultural, que vai se apresentar de forma bastante peculiar em relação às dos demais Sítios Urbanos Nacionais do Ciclo do Ouro em Minas Gerais, principalmente no que se refere à sua conformação e ao papel que a agricultura nela desempenha. Para se ilustrar conjuntamente as possibilidades que tal conceito oferece, vai se analisar aqui um plano de revitalização da paisagem cultural através da agricultura urbana, em curso no Serro, que parte justamente da compreensão do caráter rural daquele município e da conformação morfológica muito própria do seu Centro Histórico.

\section{TENTATIVAS DE DELIMITAÇÃO DE UM CONCEITO}

Apesar da verdadeira explosão por que tem passado o conceito de patrimônio desde os anos 1960, o fato é que se continuou por muito tempo a lidar de forma frequentemente estanque com os patrimônios cultural e natural, demarcando-se as áreas e pouco se pensando em sua conexão. Assim, por exemplo, a Convenção do Patrimônio Mundial da UNESCO, desde sua aprovação em 1972, vinha classificando separadamente o patrimônio cultural e o natural, lançando-se definitivamente a nova categoria de "paisagem cultural" apenas por ocasião da 16a sessão do Comitê do Patrimônio Mundial, realizado em Santa Fé, Novo México, em 1992, depois de anos de discussão sobre a essência das paisagens culturais. Com isso, a Convenção vai ser o primeiro instrumento legal internacional a reconhecer e proteger tal tipo complexo de patrimônio - focada na interação entre natureza e cultura e, ao mesmo tempo, ligado também intimamente às maneiras tradicionais de viver ${ }^{2}$. Tanto para a UNESCO quanto para o Comitê do Patrimônio Mundial, esta nova perspectiva vem representar uma importante contribuição para se abordar a questão do desenvolvimento sustentável, ao envolver mais de perto as próprias comunidades ${ }^{3}$. Dando sequência à abordagem deste conceito, a UNESCO definiu, ainda em 1999, as paisagens culturais da seguinte forma, no documento intitulado "Diretrizes operacionais para a implementação da Convenção do Patrimônio Mundial":

2 O Comitê reconheceu que as paisagens culturais representavam o "trabalho combinado da natureza e do homem", designado no Artigo 1o da Convenção. A esse respeito, confira UNESCO, 2005.

3 BANDARIN, Francesco. Foreword. In: FOWLER, 2003 


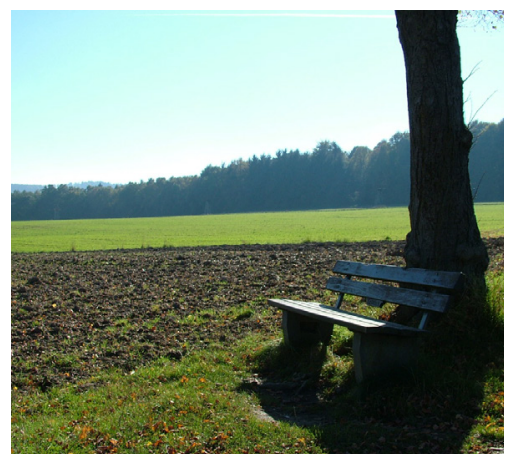

Detmold, Alemanha

Foto: Leonardo Barci Castriota
Paisagens culturais representam o trabalho combinado da natureza e do homem designado no Artigo I da Convenção. Elas são ilustrativas da evolução da sociedade e dos assentamentos humanos ao longo do tempo, sob a influência das determinantes físicas e/ ou oportunidades apresentadas por seu ambiente natural e das sucessivas forças sociais, econômicas e culturais, tanto internas, quanto externas. Elas deveriam ser selecionadas com base tanto em seu extraordinário valor universal e sua representatividade em termos de região geocultural claramente definida, quanto por sua capacidade de ilustrar os elementos culturais essenciais e distintos daquelas regiões (UNESCO, 1999).

Em 1993, o Parque Nacional Tongariro, na Nova Zelândia, se tornou o primeiro bem a ser inscrito na lista do Patrimônio Mundial, já utilizando os novos critérios, sendo colocado sob a categoria de paisagem cultural. A UNESCO assim descreve esse novo patrimônio da humanidade:

As montanhas no coração do parque têm importância cultural e religiosa para o povo Maori, e simbolizam as ligações espirituais entre esta comunidade e seu meio ambiente. O parque tem vulcões extintos e ativos, uma ampla gama de ecossistemas e algumas paisagens espetaculares ${ }^{4}$.

Hoje, 20 anos depois do início da sua utilização pela UNESCO, mais de 60 paisagens culturais já foram oficialmente inscritas na Lista do Patrimônio Mundial, inscrições que refletem também a diversidade do conceito: dos remanescentes arqueológicos do Vale Bamivan no Afeganistão até os terraços de arroz nas Filipinas, do Parque Nacional UluruKata Tjuta na Austrália até os Jardins Botânicos Reais em Kew, Inglaterra, as paisagens culturais da lista da UNESCO cobrem as diversas regiões do globo (embora a maior parte delas ainda esteja concentrada na Europa) e representam configurações variadas.

Como se pode perceber apenas pelos exemplos listados, o termo "paisagem cultural" vai abarcar uma diversidade de manifestações dos tipos de interações entre a humanidade e seu meio ambiente natural: de jardins projetados a paisagens urbanas, passando por campos agrícolas, rotas de peregrinação entre outras, como veremos. E vai ser justamente essa amplitude do termo e sua delimitação ainda um tanto indefinida e que leva a controvérsias de toda natureza, como mostram vários estudiosos, que apontam que apesar do renascimento

4 http://whc.unesco.org/en/list/421 
que esse termo vive hoje, ele ainda é marcado por um relativo desconhecimento por parte até de experts, e por uma enorme polissemia (RIBEIRO, 2007).

Ao mesmo tempo em que se mostra altamente complexa e ambígua, essa ideia começa a se espalhar, penetrando também nas políticas de patrimônio em outros níveis - nacionais, regionais e locais, e marcando uma série de iniciativas ao redor do mundo. Neste sentido, cabe se destacar, por exemplo, a ação do English Heritage, órgão inglês de preservação, que tem coordenado um "Programa de Caracterização das Paisagens Históricas", e desde 1992 vem produzindo uma descrição georeferenciada da dimensão histórica das paisagens rurais da Inglaterra, ferramenta poderosa para o seu manejo ${ }^{5}$. Nos Estados Unidos, país com longa tradição de preservação do patrimônio natural, a temática das paisagens culturais ganhou contorno definido nos anos 1980 e 1990, tendo o National Park Service, órgão de preservação nacional, desenvolvido neste período critérios para intervenções em paisagens culturais, que foram consolidados no final dos anos $1990 \mathrm{com}$ o lançamento da Preservation Brief N.36, que, aos moldes do feito em outras áreas do patrimônio, divide essas intervenções em preservação, revitalização, restauro e reconstrução ${ }^{6}$.

Várias são também as tentativas de delimitar e estabelecer categorias dentro do amplo universo abrangido pelo conceito de "paisagem cultural", que vai abarcar, como vimos, uma diversidade de manifestações da interação entre a humanidade e seu meio ambiente natural, com maiores ou menores graus de intervenção humana. Assim, por exemplo, a Cultural Landscape Foundation, organização não governamental envolvida no assunto, propõe dividir as paisagens culturais em quatro tipos: sítios históricos, que reúnem as paisagens significativas pela sua associação com um evento atividade ou pessoa histórica, tais como campos de batalhas e as cercanias das casas dos presidentes; paisagens históricas planejadas, paisagens que foram planejadas ou executadas intencionalmente por um paisagista, mestre de jardinagem, arquiteto, ou horticultor, de acordo com princípios de projeto, ou por um jardineiro amador, trabalhando num estilo ou tradição reconhecível, tais como parques, campi e propriedades rurais; paisagens históricas vernaculares, paisagens que se desenvolveram através do uso pelas pessoas cujas atividades ou ocupação moldaram

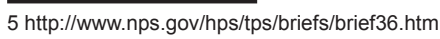

6 http://www.english-heritage.org.uk/server/show/conWebDoc.3943. A respeito de sua implementação, confira: www. landscapecharacter.org.uk/elc.html 
aquela paisagem, tais como aldeias rurais, complexos industriais e paisagens agrícolas; e paisagens etnográficas, paisagens que contêm uma variedade de bens naturais e culturais que são definidos como bens patrimoniais, tais como assentamentos contemporâneos, sítios religiosos sagrados, e estruturas geológicas massivas ${ }^{7}$.

O próprio Comitê do Patrimônio Mundial identificou e adotou três categorias de paisagem cultural, variando daquelas paisagens deliberadamente "modelada" pelo homem, passando por todo um segmento de trabalhos "combinados", até chegar aos menos evidentemente "plasmados" pelo homem (embora altamente valorizados). As três categorias extraídas das Diretrizes Operacionais do Comitê são, então, as seguintes:

(i) "uma paisagem planejada e criada intencionalmente pelo homem";

(ii) uma "paisagem que se desenvolveu organicamente" que pode ser uma "paisagem relíquia (ou fóssil)" ou uma "paisagem com continuidade";

(iii) uma paisagem cultural "associativa" que pode ser valorizada por causa das "associações religiosas, artísticas ou culturais dos elementos naturais".

Uma análise acadêmica, realizada em 2006, dos esforços combinados do Comitê do Patrimônio Mundial, dos múltiplos especialistas ao redor do mundo e das nações para aplicar o conceito de "paisagem cultural", concluiu que:

Apesar do conceito de paisagem ter se desprendido já há algum tempo de suas associações artísticas originais, (...) ainda há uma visão dominante da paisagem como uma superfície inscrita, semelhante a um mapa ou um texto, da qual o sentido cultural ou as formas sociais podem ser lidar simplesmente.

Nos últimos anos, no entanto, tal concepção começa a ser contestada, inclusive dentro dos órgãos de preservação, nacionais e internacionais, caminhando-se para uma concepção mais ampla e dinâmica da paisagem cultural. Neste sentido, é que recentemente se propôs, por exemplo, a candidatura da cidade de Buenos Aires como patrimônio da humanidade, utilizando-se de forma transformadora essa nova categoria: no dossiê encaminhado à UNESCO, combinam-se na paisagem cultural daquela cidade desde a maneira de se utilizar

7 Confira: htt p://www.tclf.org/whatis.htm 
o Rio de La Plata e suas margens até as manifestações artísticas e culturais da capital argentina como o tango e a literatura de Borges, passando pelo seu traçado e conjunto riquíssimo da arquitetura eclética. Infelizmente, essa visão ampla não encontrou acolhida no Comitê do Patrimônio Mundial, ainda fortemente marcado por uma visão eurocêntrica, que vê sempre na paisagem resquícios de ruralidade, tendo muita dificuldade em incorporar as dimensões desse conceito inovador.

\section{CENÁRIOS CONVERGENTES: BENS CULTURAIS E NATURAIS NA PAISAGEM CULTURAL DO SERRO}

Para ilustrar as possibilidades de utilização dessa perspectiva, que ilumina exatamente as interações entre os aspectos natural e cultural, material e imaterial do patrimônio, vamos tomar a cidade do Serro, localizada no "Distrito do Diamante", em Minas Gerais, a 255 quilômetros ao Norte de Belo Horizonte, e uma das poucas cidades da região da mineração a ter sua economia marcada também pela agricultura, desde o inicio. Localizada ao longo da chamada "Estrada Real", a paisagem cultural do Serro combina, como mostraremos, uma topografia específica, um significativo patrimônio edificado, uma riqueza de espécies vegetais e uma maneira tradicional de cultivar o solo, que liga o conjunto a outros de origem portuguesa.

Por muito tempo, a historiografia sobre as cidades coloniais brasileiras, muito bem representadas pela obra de Sérgio Buarque de Holanda, Raízes do Brasil (2000), apontava a sua oposição ao modelo das cidades de origem espanhola nas Américas. De acordo com seu ponto de vista, enquanto essas eram planejadas e organizadas de acordo com um padrão rigidamente ortogonal, seguindo estritamente as "Leyes de las Indias", aquelas seriam produtos de uma ocupação espontânea. Recentemente houve uma transformação na historiografia, e essa visão sofreu uma profunda revisão por autores tais como Nestor Goulart Reis Filho (Evolução urbana no Brasil, 1968) e Roberta Marx Delson (New Towns for colonial Brasil: Spatial and Social Planning of the Eighteenth Century, 1979), que mostraram a existência de cidades planejadas no período colonial e de uma política territorial exercida pela Coroa Portuguesa.

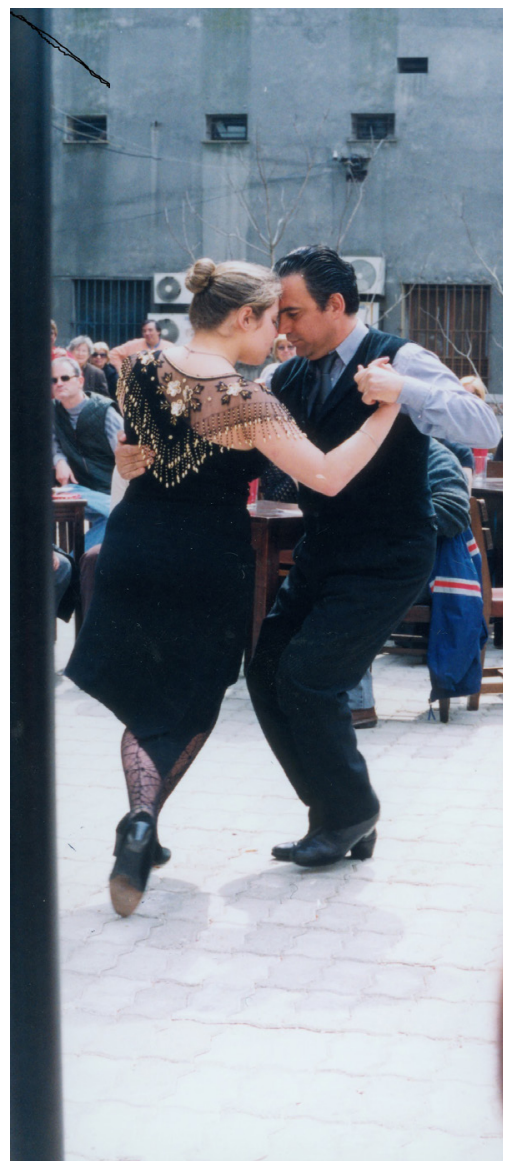

Dançando tango na rua, Buenos Aires, Argentina. Foto: Leonardo Barci Castriota 
Esta revisão levou a uma compreensão mais detalhada da forma urbana das cidades brasileiras, e várias obras recentes têm tentado estabelecer os padrões reais e complexos seguidos pelas nossas cidades tradicionais. $O$ fato é que as cidades portuguesas apresentam uma coerência formal e são estruturadas com base em uma série de princípios que podem ser observados na morfologia urbana tanto em Portugal quanto nos outros territórios além-mar, em diversos períodos históricos (TEIXEIRA, 2000). A organização das cidades no Brasil aconteceu por meio das "ordenanças" que transplantaram a organização municipal portuguesa para a Colônia, produzindo uma forma urbana muito específica que, não obstante, tem suas regras próprias, constituindo aquilo que poderíamos denominar de uma "paisagem cultural" bastante peculiar, nova ideia no campo da preservação do patrimônio que estamos explorando.

Grande parte das cidades brasileiras do inicio de nossa colonização - como o Rio de Janeiro, Salvador, e muitas outras - se desenvolveram tradicionalmente na costa, em áreas de baías. $\mathrm{O}$ caso de Minas Gerais, no entanto, foi bastante peculiar, pelas razões já mencionadas anteriormente: a maior parte das cidades aqui se desenvolveu próxima a rios e / ou em encostas suaves, ao longo da Estrada Real. O solo nessas regiões é normalmente bastante irregular e desfavorável à ocupação humana: localizando-se numa altitude geralmente elevada, a maior parte das cidades nessa região se estende por áreas acidentadas e íngremes, uma dificuldade que é aumentada pelo solo duro que faz ainda mais difíceis os trabalhos agrícolas.

A forma linear da maior parte das cidades é explicada pelo seu próprio processo de formação: em muitos casos, as cidades aparecem como uma conexão entre pequenos arraiais mineradores, erigidos ao redor de pequenas capelas. Diferentemente das cidades coloniais de origem hispânica, aqui não havia uma Plaza Mayor ou Plaza de Armas, praça principal onde a catedral convivia com os edifícios públicos - servindo esses pequenos espaços urbanos articulados pelas capelas de praças ou largos. Também diferentemente das cidades hispânicas, as cidades mineiras não seguiam um layout prévio, articulandose geralmente ao longo de uma via mais antiga, ao longo da qual começam a aparecer edificações residenciais e comerciais. Como um resultado, a forma das cidades costuma se adaptar aos contornos do terreno de uma maneira "casual": ao invés de uma malha rígida e ruas alinhadas, as cidades coloniais brasileiras - e as mineiras em particular - se espalham 


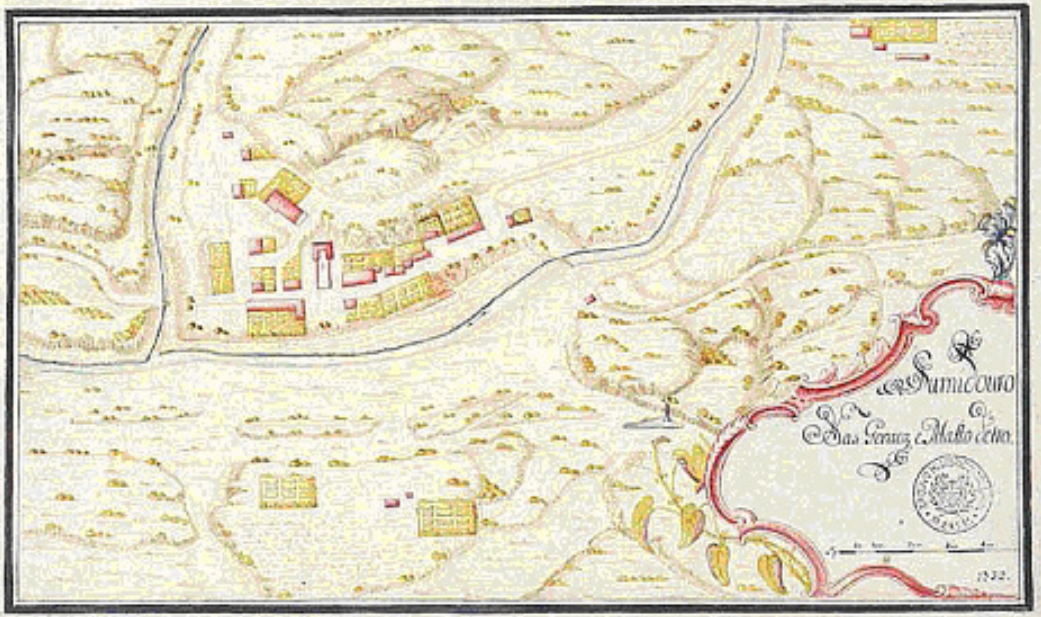

Mapa do Sumidouro, mostrando uma pequena vila articulada em torno de uma capela. Fonte: Arquivo Público Mineiro - APM

a partir do seu ponto de partida para cobrir as encostas, protegidas dos ventos mais fortes e das inundações, frequentes nas áreas mais baixas.

Se essas cidades tiveram uma fase inicial fortemente marcada por esse fenômeno "espontâneo", numa fase subsequente de desenvolvimento, pode-se observar uma ocupação "intencional" dos pontos dominantes do território para funções urbanas e edifícios significativos - civis e religiosos, edificações que iriam atrair o desenvolvimento de logradouros ao seu redor (Vasconcellos, 1977) ${ }^{8}$. Um bom exemplo deste desenvolvimento pode ser dado pela Praça Tiradentes, em Ouro Preto (MG), um espaço oficial desenvolvido no topo do Morro de Santa Quitéria, o ponto mais alto na ocupação da cidade, que separavam os dois assentamentos existentes, cuja ocupação foi planejada e executada pelo Estado. Um arranjo espacial diferente pode ser notado ali, tendendo mais para um padrão regular, mais próximo ao padrão da malha, que reflete o poder imperial e o seu poder crescentemente repressivo.

8 Esses pontos dominantes podem estar no topo das montanhas ou os pontos mais proeminentes nas meias encostas onde a cidade se desenvolve. A esse respeito, confira, VASCONCELLOS, 1977. 
Todo esse processo pode ser observado na cidade do Serro (MG), que aparece no início do século XVIII com a descoberta do ouro naquela região, tendo sido inicialmente conhecida como "Arraial das Lavras Velhas do Ivituruí", próximo aos córregos do Lucas e dos Quatro Vinténs. Graças a seu rápido crescimento, o arraial foi elevado à Vila do Príncipe em 1714, tornado-se uma comarca em 1720, com a importante responsabilidade legal-administrativa sobre quase todas as regiões Norte e Nordeste da recentemente estabelecida Província de Minas Gerais.

A região permaneceu relativamente isolada do resto do país, não apenas devido a sua distância da costa, mas por causa das leis estritas e rigorosas que tentavam impedir o contrabando de diamantes que tinha se tornado o principal produto da região. Não obstante, a Vila do Príncipe teve um notável crescimento, mesmo que não comparável ao de Ouro Preto ou ao de São João Del-Rei, no mesmo período.

A cidade do Serro mantém até hoje um esquema urbano básico, próximo àquele do século XVIII, quando a sua ocupação foi consolidada: a cidade se estende linearmente, principalmente nas meias encostas e próxima a córregos. A sua origem também é muito similar a de outras cidades mineiras: a nova cidade se formou gradualmente, articulando-se ao longo de um eixo principal que conectava dois assentamentos de mineiros, conhecidos como o "Arraial de Cima" e o "Arraial de Baixo", que correspondem, como os nomes já indicam, às partes alta e baixa da cidade, num processo que também foi mostrado por Sylvio de Vasconcellos em relação à Diamantina ${ }^{9}$. O seu crescimento seguiu uma tendência longitudinal, na direção Leste-Oeste, e a cidade se articula em torno de três eixos principais - a rua Direita, a rua de Cima e a rua do Corte, que têm um ponto de confluência na entrada da cidade na Estrada Real. No entanto, há certos traços que diferenciam a cidade do Serro de todos os outros centros históricos de Minas Gerais, e esses se relacionam especialmente a seu caráter rural, que caracteriza a região desde os seus primeiros tempos. A sua topografia é marcada pela presença de uma cadeia de montanhas e por rios, e o seu clima é o típico de montanhas. O solo é pedregoso, no entanto, fértil o suficiente, e favorável à agricultura, especialmente para o cultivo de milho, cana-de-açúcar, feijão, mandioca e banana. Com a decadência do Ciclo do Ouro, na segunda metade do século XVIII, a cidade do Serro intensificou sua atividade agrícola ${ }^{10}$. Na sua região Norte, há muitas fazendas de

9 Mais sobre esse ponto,confira CANNIGIA \& MAFFEI, 2001

10 Instituto Estadual do Patrimônio Histórico e Artístico do Estado de Minas Gerais, 2007. 
criação de gado, e a produção de queijo artesanal sempre foi tradicional na região, sendo bastante conhecida em todo o país, ao ponto do queijo do Serro ter tido seu registro como patrimônio imaterial tanto no Estado de Minas Gerais, quanto por parte do IPHAN.

Quando Augustin de Saint-Hilaire visitou o Serro, em 1817, a corrida do ouro já tinha terminado, mas ele descreveu a boa aparência da cidade, as suas ruas pavimentadas (o que não era comum na época) e a sua rica vida social. Essa vitalidade devia-se em parte a seu caráter agrícola, que impediu que o Serro, diferentemente de muitas outras cidades do Estado, tivesse uma decadência muito profunda (SAINT-HILAIRE, 1975, p.145).

Enquanto as cidades hispano-americanas tinham um centro único, organizado em torno da Plaza Mayor, e eram organizadas regularmente, em malha, estas também tinham limites muito precisos, distinguindo-se claramente entre o urbano e o rural. De forma diferente, a cidade portuguesa tendia a ter um contorno impreciso, com o urbano fundindo-se lentamente no rural, à medida em que a cidade ficava menos densa e se caminhava para a periferia.

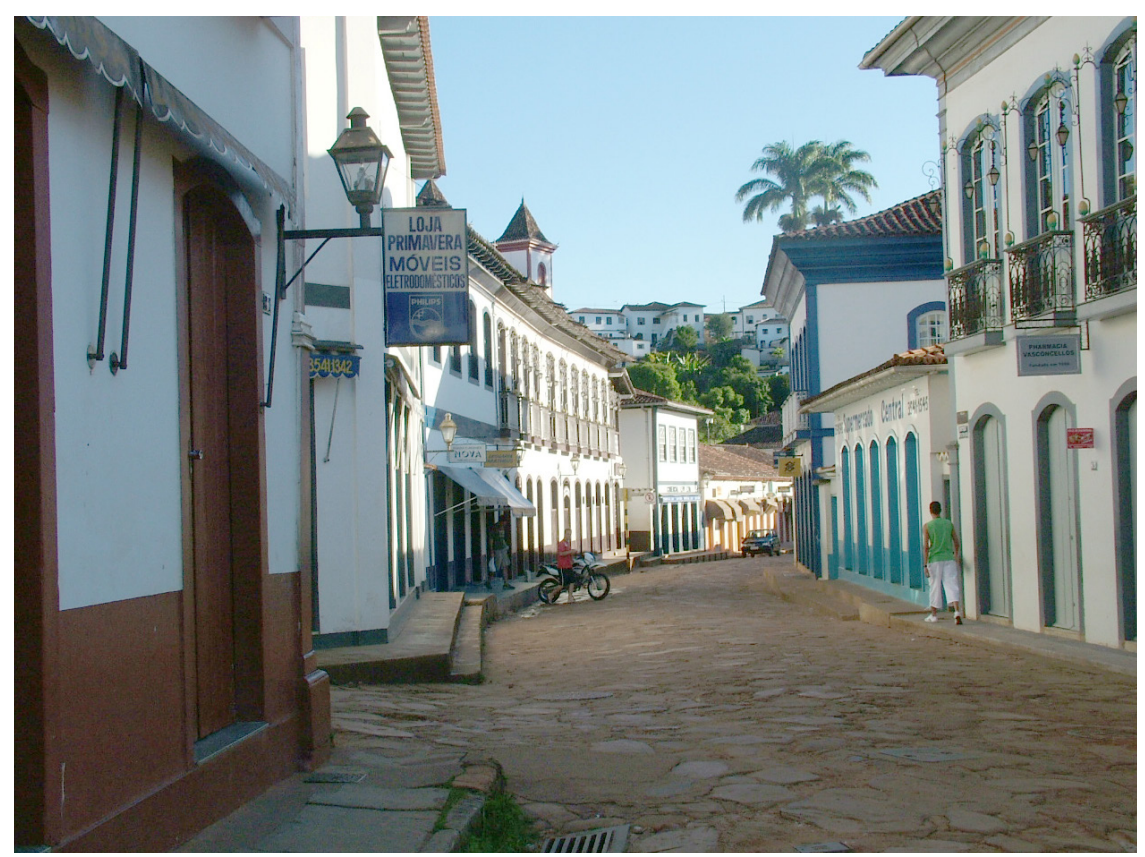


Nas periferias dessas cidades, a ocupação gradualmente se tornava menos densa e os lotes, maiores, muitas vezes conhecidos como "sítios", serviam para a prática da agricultura familiar. No caso do Serro, esse traço é muito perceptível, e não apenas na periferia, na medida em que aqui se conserva uma baixa ocupação dos lotes, mantendo-se a relação cheio-vazio da época colonial: lotes grandes e uma ocupação pouco densa marcam todo o conjunto urbano do Serro, e não apenas as periferias.

Outro traço morfológico definidor da paisagem do Serro é a predominância de terrenos muito íngremes, com declividades variando de $30 \%$ a $100 \%$, o que contribui fortemente para moldar a arquitetura local, marcada por uma tipologia específica de sobrados que vão acomodar mais andares num dos lados da edificação, podendo atingir até quatro pavimentos, embora do outro lado apareçam apenas um ou dois desses andares.

\section{O DESAFIO DA CONSERVAÇÃO DAS PAISAGENS CULTURAIS E A AGRICULTURA}

Conservar as paisagens culturais é um dos desafios mais complexos com os que se depara a área do patrimônio hoje. Se a sua conceituação já se mostra uma tarefa difícil, tal dificuldade se aprofunda quando se passa para a formulação de estratégias para o tratamento dessa categoria especial de patrimônio. O National Park Service americano, órgão responsável pela formulação de políticas de patrimônio nos Estados Unidos, país com longa tradição de tratamento do patrimônio natural, vem se empenhando significativamente neste sentido, emitindo ainda em 1992 diretrizes relativas às paisagens culturais, distinguindo-se entre os diversos tipos de intervenção - preservação, restauração, revitalização das paisagens. Não se trata de tarefa fácil, já que não se restringe à dimensão estética das paisagens, devendo um correto tratamento das mesmas envolver simultaneamente tanto a dimensão funcional dessas paisagens, quanto a sua dimensão ecológica11.

A significação e a autenticidade dessas paisagens vão envolver também elementos que se relacionam com a dimensão imaterial do patrimônio, dependendo freqüentemente da continuidade e da vitalidade de sistemas tradicionais de cultura e de produção, que criaram ao longo do tempo padrões característicos de uso da terra e um sentido único de lugar.

11 A esse respeito, confira HOHMAN, Mediating ecology and history. In: LONGSTRETH (2008). 
Hoje muitos desses usos tradicionais da terra - e os produtos a eles relacionados - que eram largamente aceitos sem maior reflexão, correm o perigo de serem desestabilizados e destruídos. Mudanças demográficas, o aumento do valor da terra, a industrialização da produção agrícola e a competição dos mercados mundiais estão revolucionando as relações sociais e econômicas tradicionais com a terra. A velocidade e o alcance dessas mudanças são inéditas e têm implicação significativa na gestão do patrimônio cultural, que incluem a fragmentação e a mudança de paisagens culturais, a perda de mercado dos produtos tradicionais e mesmo a erosão da identidade e distinção regionais. Assim, preservar as paisagens culturais significa, muitas vezes, defrontar-se com as formas tradicionais de agricultura.

Não é por outra razão que a UNESCO, ao implementar a categoria de "paisagem cultural", incluiu na lista do Patrimônio Mundial algumas paisagens relacionadas diretamente à agricultura, entre as quais poderíamos citar, como exemplo, a "Paisagem cultural da região de vinhedos de Tokaj”, na Hungria, incluída na Lista em 2002. Ao justificar essa inclusão, a UNESCO escreve:

A paisagem cultural de Tokaj demonstra visualmente a longa tradição da produção do vinho nesta região de montanhas baixas e vales de rios. O padrão intricado dos vinhedos, fazendas e pequenas cidades com sua rede histórica de porões de fabricação de vinho, ilustra cada faceta da produção dos famosos vinhos de Tokaj, cuja qualidade e gestão têm sido estritamente regulamentados por quase três séculos.

Uma outra tentativa importante nesta direção, que entrelaça ecologia, patrimônio natural e conhecimentos tradicionais, vai ser o estudo de P. S. Ramakrishnan, da Universidade Jawaharlal Nehru, de Nova Deli, Índia, que define o que denomina de "Sistemas de patrimônio agrícola engenhosos globalmente importantes" ("Globally Important Ingenious Agricultural Heritage Systems" - GIAHS), categoria criada para designar aqueles sistemas agrários complexos mantidos pelas sociedades tradicionais, que são geridas de forma casual ou com baixa intensidade, como um componente integral de uma paisagem cultural, conservada pelas sociedades através de um sistema de valores que tem fortes interconexões sócio-culturais com a paisagem na qual se localizam. Eles são produtos de interações eco-culturais no tempo e no espaço, e podem ainda estar se desenvolvendo ${ }^{12}$.

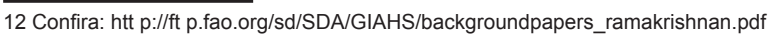


A seu ver, em tempos de globalização, faz-se ainda mais necessário o conhecimento, registro e apoio a essas práticas tradicionais, altamente ameaçadas, e cujo desaparecimento não significaria apenas uma perda cultural, mas também uma contribuição negativa para o empobrecimento ecológico do planeta.

Neste sentido, parece-nos promissora a ênfase que tem sido dada no Brasil atualmente a questão da agricultura familiar, vista agora como possível protagonista das políticas orientadas para o desenvolvimento rural. Isso fica ainda mais patente quando se percebe que em muitas das políticas públicas hoje introduzidas em nosso país, se pretende ampliar o conceito de desenvolvimento com a introdução da noção de sustentabilidade, incorporando outras esferas, além da estritamente econômica, tais como: a educação, a saúde e a proteção ambiental (Pronaf, 1996, p. 6-7).

Como anota Maria José Carneiro:

Há décadas relegada a segundo plano e até mesmo esquecida pelo Estado, a agricultura familiar e a sua base fundiária - a pequena propriedade - têm sobrevivido em meio à competição de condições e recursos orientados para favorecer a grande produção e a grande propriedade - setores privilegiados no processo de modernização da agricultura brasileira. $O$ aumento da produtividade, associado ao consumo de tecnologia, tem fundamentado a ação e o discurso modernizadores até aqui. (CARNEIRO, 1997)

Assim, as propostas recentes para o fortalecimento da agricultura familiar voltadas para as demandas dos trabalhadores - sustentadas em um modelo de gestão social em parceria com os agricultores familiares e suas organizações - vêm representar "um considerável avanço em relação às políticas anteriores", o que pode ser observado já no texto do Pronaf, de 1996, quando se propõe a construir um "novo paradigma de desenvolvimento rural para o Brasil, sem os vícios do passado" (Pronaf, 1996, p.14).

Dentro dessa perspectiva, desempenha um papel importante a agricultura urbana, que é realizada em pequenas áreas dentro de uma cidade, ou no seu entorno (periurbana), e destinada à produção de cultivos para utilização e consumo próprio ou para a venda em pequena escala, em mercados locais. Como anota o engenheiro-agrônomo Alexandre Dinnys Roese, da EMBRAPA/CPAP, a agricultura urbana vai diferir da agricultura tradicional (rural) em vários aspectos: 
Inicialmente, a área disponível para o cultivo é muito restrita na agricultura urbana. Além disso, há escassez de conhecimentos técnicos por parte dos agentes/ produtores diretamente envolvidos; freqüentemente não há possibilidade de dedicação exclusiva à atividade; a atividade destina-se, normalmente, para utilização ou consumo próprio; há grande diversidade de cultivos; e a finalidade da atividade é distinta, pois normalmente não é requisito para a agricultura urbana a obtenção de lucro financeiro. (ROESE, 2003)

Apesar dessas distinções, pode-se observar uma relação muito forte entre a agricultura rural/ tradicional e a agricultura urbana, como anota aquele autor, na medida em que esta última vai ser normalmente praticada mais intensamente "em regiões ou municípios que tenham tradição agrícola no meio rural". Apesar de sua valorização ser recente, a agricultura urbana vai ser, na verdade, uma prática antiga, constituindo parte importante do saber fazer das comunidades. O que se nota, recentemente, é que sua retomada em comunidades urbanas de baixa renda tem gerado resultados muito positivos, contribuindo tanto para a segurança alimentar das famílias envolvidas, quanto para o fortalecimento dos vínculos de vizinhança e para a valorização da cultura e do conhecimento popular. Assim, não há dúvida que elementos importantes do patrimônio cultural de um povo estão imbricados nessa prática centenária. Exatamente neste ponto é que vemos a possibilidade de se entrelaçarem temas até então estanques, e que vamos procurar integrar neste projeto: por um lado, a questão da agricultura familiar, em sua versão urbana; por outro a questão da preservação do patrimônio cultural, em suas vertentes material (paisagem cultural) e imaterial (técnicas tradicionais), tudo isso perpassado pela perspectiva contemporânea da sustentabilidade. Essa desejável integração entre as dimensões físicas e técnicas e a dimensão cultural é - embora não explicitamente - pressuposto das diversas políticas setoriais. Assim, vai ser interessante perceber, por exemplo, como o próprio Programa Nacional do Patrimônio Imaterial em implantação pelo IPHAN, através de diversas parcerias, com instituições dos governos federal, estadual e municipal, universidades, organizações não governamentais, entre outros, estabelece entre suas diretrizes de políticas de fomento a ideia de se promover a salvaguarda de bem cultural imaterial por meio de apoio às condições materiais que propiciam sua existência, bem como pela ampliação dos acessos aos benefícios gerados por essa preservação ${ }^{13}$.

13 Mais a respeito do Programa Nacional do Patrimônio Imaterial (PNPI) do IPHAN, confira http://portal.iphan.gov.br/ pagina/detalhes/61 
Visa geral do Serro, 2009

Fonte: Leonardo Barci Castriota

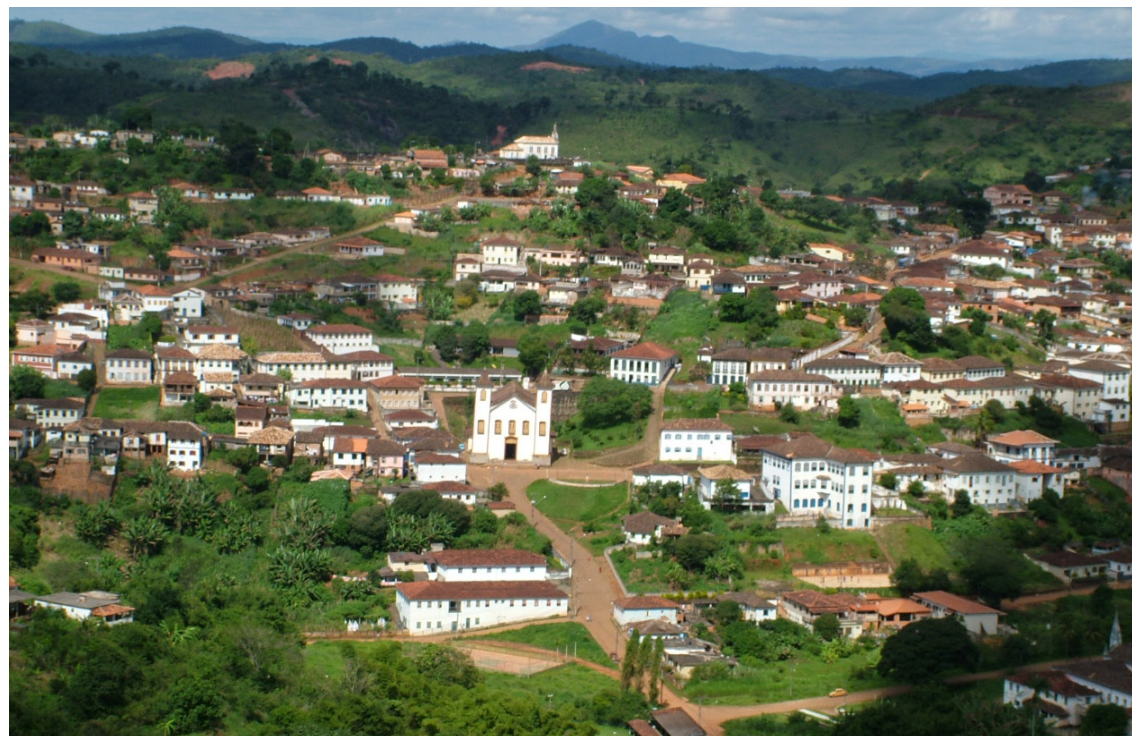

\section{UM PLANO DE PRESERVAÇÃO DA PAISAGEM CULTURAL: POSSIBILIDADES}

Metchild Rossler, do Centro do Patrimônio Mundial da UNESCO, no seminário FORUM UNESCO realizado em 2005, aponta a íntima ligação entre a proteção dos valores e do patrimônio intangíveis e das paisagens naturais, sendo que manutenção do tecido social, do conhecimento tradicional, dos sistemas de uso da terra e das práticas nativas são essenciais para a sua sobrevivência. (UNESCO, 2005) As paisagens naturais seriam, a seu ver, aqueles lugares por excelência onde se pode aprender sobre a relação entre o povo, a natureza e os ecossistemas e como isso conforma a cultura, a identidade e enriquece a diversidade cultural e biológica. (UNESCO, 2005) Esta vai ser a ideia motriz de um plano que vem sendo desenvolvido no município do Serro, e que se propõe a promover a revitalização da paisagem cultural através da agricultura urbana, partindo justamente da compreensão do caráter rural daquele município, corporificado nas práticas agrícolas tradicionais, e da conformação morfológica muito própria do seu centro histórico. Assim este projeto se propõe a salvaguardar um patrimônio imaterial - as práticas, conhecimentos e 


\begin{tabular}{|l|l|l|l|}
\hline Cultivo & $\begin{array}{l}\text { Solo } \\
\text { Água } \\
\text { Sementes } \\
\text { Clima }\end{array}$ & $\begin{array}{l}\text { Elementos naturais } \\
\text { apropriados }\end{array}$ & \multirow{2}{*}{$\begin{array}{l}\text { Saber fazer } \\
\text { tradicional }\end{array}$} \\
\hline Preparo & $\begin{array}{l}\text { Culinária local } \\
\text { Variedade de produtos } \\
\text { Tempero } \\
\text { Receitas }\end{array}$ & Elementos culturais & \\
\hline Conservação & $\begin{array}{l}\text { Doces } \\
\text { Geleias } \\
\text { Licores } \\
\text { Rapadura } \\
\text { Fubá }\end{array}$ & $\begin{array}{l}\text { Métodos tradicionais - } \\
\text { agregam valores aos } \\
\text { produtos da agricultura }\end{array}$ & \\
\hline
\end{tabular}

técnicas tradicionais relativos ao cultivo, preparo e conservação tanto de alimentos quanto de plantas medicinais, no Serro (MG), não só através do seu inventariamento, mas também através de um plano de salvaguarda, que passa pela revitalização da paisagem do núcleo urbano e do seu entorno através da prática sustentável da agricultura familiar. Para isso, combina-se pesquisa com extensão, num entrelaçamento ainda inédito em nosso país das temáticas do planejamento urbano, preservação do patrimônio urbano e cultural e o incentivo à agricultura familiar.

Carlos Fernando de Moura Delphim, do IPHAN, em sua "Proposta de intervenções paisagísticas em sítios do centro histórico e adjacências na cidade do Serro, MG", documento produzido para o IPHAN no ano 2000 , já chamava a atenção para a riqueza contida naquela localidade e a necessidade de preservá-la:

O Serro é depositário de espécies domésticas do patrimônio genético, algumas em vias de extinção. Na casa dos Otoni serviu-se uma variedade de mandioca inigualável no sabor, tamanho e maciez. No pomar de uma residência reencontrei uma variedade de mexerica pela qual vinha procurando há anos. Conhecia-a como laranja-cravo. Ali dão-lhe o nome de cravina. O moderno interesse puramente comercial por novas variedades de híbridos e a facilidade de se comprar enxertos destas variedades é responsável pelo desaparecimento de muitos cultivares tradicionais de frutas e legumes. A cidade que ainda possui exemplares dessas espécies deve preservá-las com o mesmo zelo que preserva suas igrejas. $O$ patrimônio genético só assume seu pleno valor quando os recursos naturais se associam ao conhecimento de formas para seu uso, sobretudo de formas peculiares, como é o caso de usos culinários como o "fubá insuado" e o cuscuz, feito também com fubá. (DELPHIM, 2000, p. 2-3).
Elementos culturais relacionados às práticas agricolas

Proposta do programa de reabilitação da paisagem Fonte: Leonardo Barci Castriota, tratada

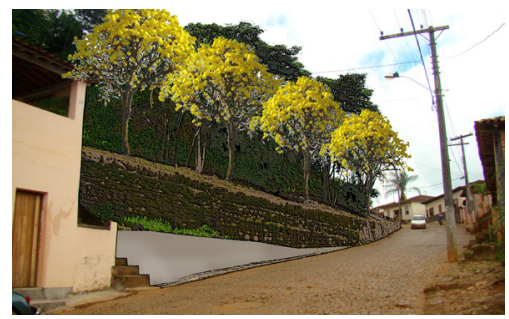


Em sua exposição, já podemos perceber o entrelaçamento que se dá nas práticas agrícolas, entre os elementos naturais e culturais: o rico "patrimônio genético" só assumiria seu pleno valor quando associado "ao conhecimento de formas para seu uso". O quadro a seguir, tenta ilustrar, de forma gráfica, alguns desses elementos - naturais e culturais - que compõem o saber fazer tradicional ligado à produção, preparo e conservação dos alimentos:

Cabe anotar aqui que a paisagem do núcleo urbano vai ter uma forte presença dos vazios, grande parte deles ocupado pelo cultivo de diversas espécies, prática que vem desde o período colonial, como atestado pelos diversos viajantes que por lá passaram. Saint Hilaire, em seu livro Viagens pelas províncias do Rio de Janeiro e Minas Gerais, já identifica ali plantações de bananeiras, mamoeiros, laranjeiras, pés de café, couve, algumas espécies de curcubitáceas, entre outros, cultivadas nos quintais de cada casa no núcleo urbano. Das janelas que se abrem para o campo, descreve, goza-se de agradável panorama: avistam- se as casas próximas entremeadas de massas espessas de verdura formada pelo arvoredo dos jardins; mais além descortina-se o vale estreito que se estende ao pé da cidade e em cujo fundo corre o quatro vinténs;... (HILAIRE, 1938). O aspecto de "jardim" dos amplos quintais acidentados - conservados até hoje - faz com que a paisagem do Serro se aproxime mesmo a de algumas configurações semelhantes no mundo de origem lusitana, como, por exemplo, às da llha da Madeira.

No entanto, hoje se percebe uma perda e descaracterização dessa paisagem, em grande parte provocada pela má utilização da agricultura urbana: terraceamentos mal feitos, espécimes inadequadas à topografia, entre outros, atestam a perda progressiva do saber fazer da agricultura urbana tradicional, que sempre caracterizou o conjunto do Serro. Assim, faz-se urgente o inventariamento e a salvaguarda deste saber fazer tradicional, não só para se evitar o seu desaparecimento iminente, mas para alavancar a preservação da paisagem cultural característica daquele conjunto tombado, ao mesmo tempo em que, num trabalho

\begin{tabular}{|l|l|}
\hline \multirow{4}{*}{$\begin{array}{c}\text { Plano de revitalização da } \\
\text { paisagem cultural do Serro }\end{array}$} & $\begin{array}{l}\text { Programa de salvaguarda das práticas, conhecimentos e técnicas tradicionais relativas ao } \\
\text { cultivo, preparo e conservação dos alimentos e plantas medicinais }\end{array}$ \\
\cline { 2 - 2 } & Programa de reabilitação da paisagem \\
\cline { 2 - 2 } & Programa de fortalecimento econômico \\
\cline { 2 - 2 } & Programa de fortalecimento institucional \\
\hline
\end{tabular}


de extensão agrícola, se estimula a agricultura familiar num núcleo marcado por um baixo nível de renda.

Trata-se, assim, de um projeto inédito e exemplar na área da extensão agrária e da preservação do patrimônio em nosso país: pela primeira vez, no Brasil, propõe-se um projeto de resgate das práticas agrícolas tradicionais que servirá de subsídio para se tratar e preservar de forma sustentável a "paisagem cultural" de um núcleo urbano tombado, categoria que, como vimos, começa a ser utilizada mundialmente. Combina-se, na perspectiva da paisagem cultural, a preservação do patrimônio material (o conjunto urbano tombado) e imaterial (práticas, conhecimentos e técnicas tradicionais relativos ao cultivo, preparo e conservação em áreas urbanas, tanto de alimentos quanto de plantas medicinais).

Finalmente, cabe destacar, mais uma vez, o caráter de sustentabilidade da proposta: ao se traçar um plano de salvaguarda de um saber fazer tradicional para através dele se perseguir a revitalização da paisagem cultural do Serro, está se abordando, simultaneamente, a dimensão cultural e paisagística, como também as suas bases sociais e econômicas. A agricultura urbana parece-nos representar uma importante atividade econômica alternativa para a população de um município pobre e com baixo índice de Desenvolvimento Humano (IDH). Assim, este projeto vem atender às diretrizes do Programa Nacional do Patrimônio Imaterial, ao oferecer para os moradores da cidade a oportunidade de perceber a paisagem como patrimônio a ser preservado, através justamente do resgate e preservação de um saber fazer tradicional, que também Ihes reverta em benefícios econômicos, garantindo assim a sua sustentabilidade.

Numa perspectiva multicefálica, o plano conjuga ao lado de um "Programa de salvaguarda das práticas conhecimentos e técnicas tradicionais relativas ao cultivo, preparo e conservação dos alimentos e plantas medicinais", o "Programa de reabilitação da paisagem", combinando intervenções físicas e projetos de ação cultural, ao lado ainda de um Programa de fortalecimento econômico e de um Programa de fortalecimento institucional, como pode ser visualizado no quadro seguinte.

Proposto em 2007, esse trabalho vem sendo executado, com o patrocínio do Programa MONUMENTA do Governo federal, por uma ampla equipe multidisciplinar - arquitetos, antropólogos, geógrafos, agrônomos, historiadores, entre outros profissionais -, como seria

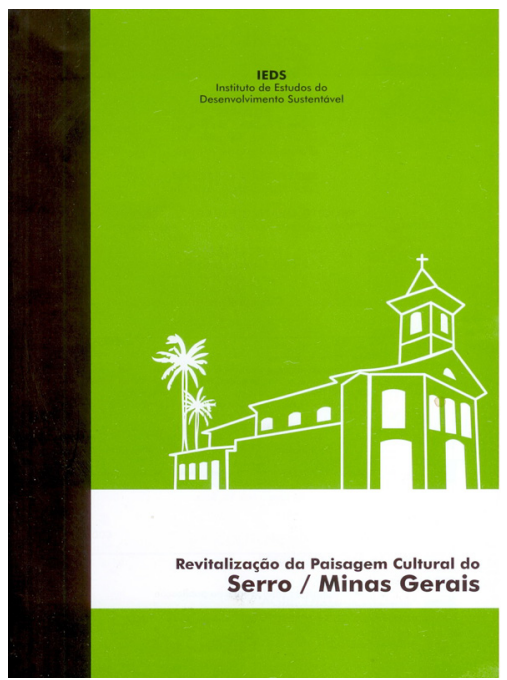

Cartilha preparada para o programa de reabilitação da paisagem 
de se esperar num projeto dessa natureza, que visa o complexo tema da paisagem cultural. Já foram finalizados os diagnósticos e o planejamento prévio, e neste momento, a equipe trabalha com a Prefeitura local na preparação de um plano estratégico para as diversas ações envolvidas, dentre as quais estão sendo eleitos alguns projetos pilotos. No entanto, já se pode adiantar que um dos subprodutos mais importantes e articulador das ações é uma "Lei de Preservação da Paisagem Cultural", que incorpora desde diretrizes de uso e ocupação para a área tratada, até um completo programa de agricultura urbana, passando pela criação de um fundo rotativo para financiamento das atividades.

Este projeto tem um sentido prospectivo, articulando uma proposta de preservação da paisagem cultural, que explora as suas diversas dimensões. Ao lado dessa dimensão investigativa, parece-nos inegável também que o projeto terá um grande impacto no que se refere ao desenvolvimento social e cultural, local e regional. Trata-se, afinal, de se mudar a "atitude" da população frente à paisagem local, estimulando-a a recuperar práticas, conhecimentos e técnicas tradicionais, que será muito útil no que se refere ao tratamento a ser dispensado aos vazios urbanos agriculturáveis. Ao mesmo tempo, estará se oferecendo uma alternativa real de geração de renda para a população de um município pobre e com baixo IDH. Os ganhos sociais são óbvios nesse caso: melhoria na renda, no abastecimento e mesmo na saúde da população local, com a possibilidade do cultivo e manipulação de ervas medicinais. Já os ganhos culturais também são de grande monta, podendo se destacar a recuperação e preservação de saber fazer tradicional, no que se refere ao cultivo, preparo e conservação de alimentos e ervas medicinais, e a recuperação e preservação da paisagem cultural, única no país. 


\section{REFERÊNCIAS BIBLIOGRÁFICAS}

CANNIGIA, G.; MAFFEI, G.L. (2001). "Interpretation basic building: architectural composition an building typology”. Firenze, Alínea.

CARNEIRO, M. J. (1997). "Política pública e agricultura familiar: uma leitura do Pronaf". Estudos Sociedade e Agricultura, 8.

CASTRIOTA, L. B. (2009). "Paisagem cultural e sustentabilidade". Belo Horizonte, Editora da UFMG, IEDS.

CASTRIOTA, L. B. (2008). "Patrimônio Cultural: Conceitos, políticas, instrumentos". São Paulo: Belo Horizonte, Annablume, IEDS.

CHENEY, G. A. (2004). "Journey on the Estrada Real: Encounters in the Mountains of Brazil". Chicago, Academy.

CHOAY, F. (2000). “A alegoria do patrimônio”. São Paulo, UNESP.

CONTI, A. (2014). "La continuidad en un mundo en cambio permanente". In: LÓPEZ MORALES, J.; VIDARGAS, F. (2014). "Los nuevos paradigmas de la conservación del patrimonio cultural. 50 años de la Carta de Venecia". Mexico: Instituto Nacional de Antropología e Historia.

D'ASSUMPÇÃO, L. R. (1989). “Considerações sobre a formação do espaço urbano setecentista nas Minas". Revista do Departamento de História, Belo Horizonte, v.9.

DELPHIM, C. F. (2000). "Proposta de intervenções paisagísticas em sítios do centro histórico e adjacências na cidade do Serro, MG". Rio de Janeiro, IPHAN.(digitado)

DELSON, R. M. (1979). "Novas vilas para o Brasil-Colônia: planejamento espacial e social no século XVIII". Brasília, Alva; CIORD.

FOWLER, P. J. (2003). "World Heritage Cultural Landscapes: 1992-2002". Paris: UNESCO World Heritage Center, 2003. (World Heritage Paper, 6) Disponível em: <http://unesdoc.unesco.org/ images/0013/001331/133121e.pdf>. Acesso em: 10 mar. 2015.

HOLANDA, S. B. (1989). "Raízes do Brasil”. Rio de Janeiro, Rocco.

HILAIRE, S. (1938). “Viagens pelas províncias do Rio de Janeiro e Minas Gerais”. São Paulo: Cia. Editora Nacional. Tomo I. 1938. 
LE BERRE, M. (1999). "Synthetic report of the Expert Meeting on African Cultural Landscapes". Disponivel em: <http://whc.unesco.org/archive/tiwi99.pdf, 1999>. Acesso em: 24 mar. 2009.

LONGSTRETH, R. (2008). "Cultural Landscapes: Balancing nature and heritage in preservation practices". Minessota: University of Minessota Press.

RAMAKRISHNAN, P.S. "Globally Important Ingenious Agricultural Heritage Systems (GIAHS): An EcoCultural Landscape Perspective”. Disponível em: <ftp://ftp.fao.org/sd/SDA/GIAHS/ backgroundpapers_ ramakrishnan.pdf>. Acesso em: 10 mai. 2014.

REIS FILHO, N. G. (2000). “Contribuição ao estudo da evolução urbana do Brasil 1500-1720". São Paulo, Perspectiva.

RIBEIRO, R. W. (2007). "Paisagem Cultural e Patrimônio". Brasília, Instituto do Patrimônio Histórico e Artístico Nacional (IPHAN).

SAINT HILLAIRE, A. (1939). "Viagens pelas províncias do Rio de Janeiro e Minas Gerais". São Paulo, Cia. Editora Nacional.

UNESCO (s/d). "Operational Guidelines for the Implementation of the World Heritage Convention". Disponivel em: <http://whc.unesco.org/opgutoc.htm>. Acesso em: 7 mar. 2009.

UNESCO (2005). Documento Conceptual. Reunión de Expertos sobre Paisajes Culturales en El Caribe: Estrategias de identificación y salvaguardia. Santiago de Cuba, p. 7-10.

VASCONCELLOS, S. (1977). "Vila Rica”. São Paulo, Perspectiva.

VASCONCELLOS, S. (1980). "A Formação urbana do Arraial do Tejuco". In: Arquitetura civil II. São Paulo: FAUUSP; MEC; IPHAN. p. 99-115. 